\title{
Propagation of low frequency geomagnetic field fluctuations in Antarctica: comparison between two polar cap stations
}

\author{
L. Santarelli, S. Lepidi, and L. Cafarella \\ Istituto Nazionale di Geofisica e Vulcanologia, Roma, Italy \\ Received: 10 May 2007 - Revised: 17 October 2007 - Accepted: 31 October 2007 - Published: 29 November 2007
}

\begin{abstract}
We conduct a statistical analysis of the coherence and phase difference of low frequency geomagnetic fluctuations between two Antarctic stations, Mario Zucchelli Station (geographic coordinates: $74.7^{\circ} \mathrm{S}, 164.1^{\circ} \mathrm{E}$; corrected geomagnetic coordinates: $80.0^{\circ} \mathrm{S}, 307.7^{\circ} \mathrm{E}$ ) and Scott Base (geographic coordinates: $77.8^{\circ} \mathrm{S} 166.8^{\circ} \mathrm{E}$; corrected geomagnetic coordinates: $80.0^{\circ} \mathrm{S} 326.5^{\circ} \mathrm{E}$ ), both located in the polar cap. Due to the relative position of the stations, whose displacement is essentially along a geomagnetic parallel, the phase difference analysis allows to determine the direction of azimuthal propagation of geomagnetic fluctuations. The results show that coherent fluctuations are essentially detectable around local geomagnetic midnight and, in a minor extent, around noon; moreover, the phase difference reverses in the night time hours, indicating a propagation direction away from midnight, and also around local geomagnetic noon, indicating a propagation direction away from the subsolar point. The nigh time phase reversal is more clear for southward interplanetary magnetic field conditions, suggesting a relation with substorm activity.

The introduction, in this analysis, of the Interplanetary Magnetic Field conditions, gave interesting results, indicating a relation with substorm activity during nighttime hours.

We also conducted a study of three individual pulsation events in order to find a correspondence with the statistical behaviour. In particular, a peculiar event, characterized by quiet magnetospheric and northward interplanetary magnetic field conditions, shows a clear example of waves propagating away from the local geomagnetic noon; two more events, occurring during southward interplanetary magnetic field conditions, in one case even during a moderate storm, show waves propagating away from the local geomagnetic midnight.
\end{abstract}

Keywords. Magnetospheric physics (MHD wave and instabilities; Polar cap phenomena; Solar wind-magnetosphere interactions)

Correspondence to: S. Lepidi

(lepidi@ingv.it)

\section{Introduction}

The study of geomagnetic field variations in Antarctica is particularly important in that local field lines reach magnetospheric boundary regions, such as the magnetopause and the polar cusp, where several phenomena which generate magnetospheric ULF waves take place (Arnoldy et al., 1988 and references therein). Moreover, these local field lines can directly connect to the interplanetary magnetic field (IMF), giving rise to a direct access of solar wind particles in the magnetosphere and to phenomena related to magnetic energy release and particle acceleration (Gonzalez et al., 1999; Lui, 2001; Phan et al., 2005).

Due to the difficulty in deploying and managing instruments in polar regions, up to a few years ago the geomagnetic data sets at extreme latitudes were scarce and fragmentary; in the last years however, there has been a common effort in establishing new stations in Antarctica; a few of Antarctic observatories are even part of the INTERMAGNET programme, so their data are easily available to the whole scientific community.

The Italian geomagnetic observatory Mario Zucchelli Station (TNB, formerly Terra Nova Bay; the base name was changed in 2004) is operating since the austral summer 198687 (Meloni et al., 1997). The availability of long series of data allowed us to conduct several studies to characterize the ULF pulsation activity and its relation with solar wind (SW) parameters (review by Villante et al., 2000). In particular, for pulsations in the Pc5 frequency range, we found that the power level maximizes around local geomagnetic noon, when the station is closer to the polar cusp (see also Ballatore et al., 1998), and that the fluctuation power is well related to the SW speed (Santarelli et al., 2003), indicating a wave source related to the Kelvin-Helmholtz instability (KHI) on the magnetopause (Atkinson and Watanabe 1966). Moreover, in the average daytime spectra, it was clear the presence of power enhancements at discrete frequencies, of the order of few $\mathrm{mHz}$ (Villante et al., 1997), which can be interpreted in terms of global magnetospheric cavity/waveguide modes (Ziesolleck and McDiarmid, 1995, and references therein).

Published by Copernicus Publications on behalf of the European Geosciences Union. 
Table 1. Geographic coordinates, IGRF02 corrected geomagnetic coordinates and times in UT of the geomagnetic local noon for the two stations.

\begin{tabular}{llllll}
\hline Station & $\begin{array}{l}\text { Geographic } \\
\text { latitude }\end{array}$ & $\begin{array}{l}\text { Geographic } \\
\text { longitude }\end{array}$ & $\begin{array}{l}\text { Corr. Geom. } \\
\text { latitude }\end{array}$ & $\begin{array}{l}\text { Corr. Geom. } \\
\text { longitude }\end{array}$ & $\begin{array}{l}\text { MLT noon } \\
\text { (UT) }\end{array}$ \\
\hline TNB & $74.7^{\circ} \mathrm{S}$ & $164.1^{\circ} \mathrm{E}$ & $80.0^{\circ} \mathrm{S}$ & $306.9^{\circ} \mathrm{E}$ & $20: 11$ \\
$\mathrm{SBA}$ & $77.8^{\circ} \mathrm{S}$ & $166.8^{\circ} \mathrm{E}$ & $79.9^{\circ} \mathrm{S}$ & $326.3^{\circ} \mathrm{E}$ & $19: 01$ \\
\hline
\end{tabular}

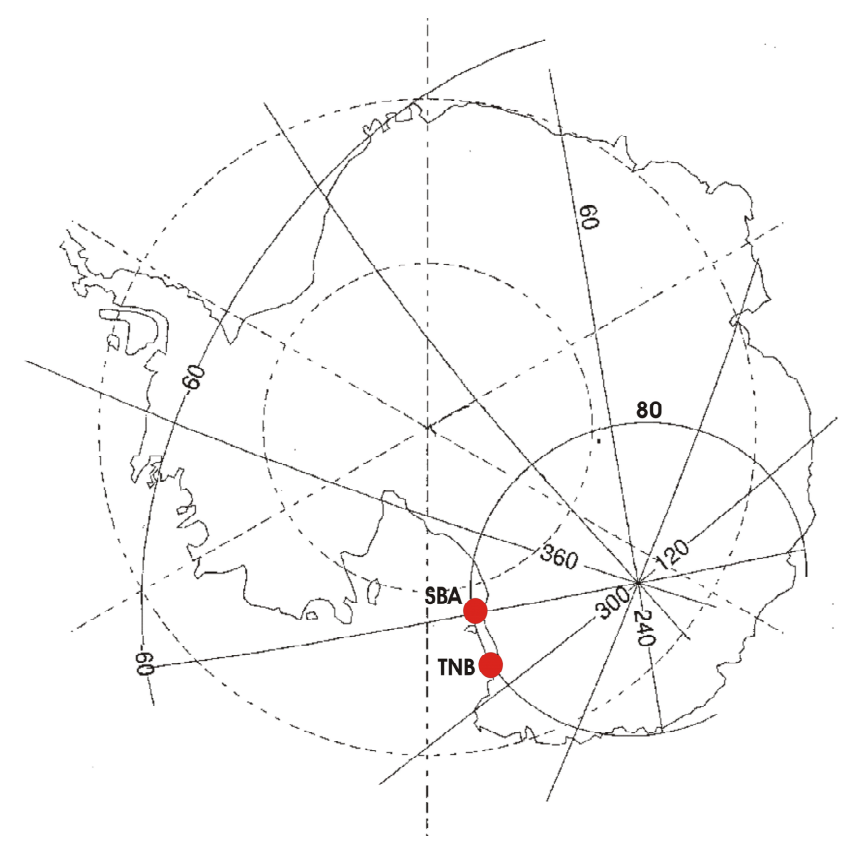

Fig. 1. Location of the two Antarctic bases TNB and SBA. The geographic and the corrected geomagnetic coordinate systems are indicated, as dashed and solid lines, respectively.

Interesting information on Pc5 pulsations have been obtained also from a statistical study of the diurnal pattern of their polarization sense (Lepidi et al., 1999); the result are in agreement with a scenario of waves propagating away from the noon and midnight sector and with local field line resonance phenomena occurring at lower latitudes (Samson, 1972). A comparison between ULF waves observed at different high latitude stations in Antarctica has shown that cap pulsations are decoupled from the activity observed at auroral latitudes, while coherent fluctuations can be observed within the polar cap, expecially in association with night time phenomena (Lepidi et al., 2003, Yagova et al., 2002, 2004).

The results achieved so far suggested us to further investigate the Pc5 pulsation characteristics focusing on their propagation direction, which can give information on the generation region and mechanism. For this purpose, we statistically analyzed the pulsations simultaneously detected at the two Antarctic geomagnetic observatories TNB and Scott Base
(SBA), which are located at the same geomagnetic latitude with 1-h difference in magnetic local time MLT (see Table 1 and Fig. 1). In this sense, the presence of a time delay (detectable as a phase difference for pulsation events) between the observations at the two stations, indicates a propagation along the azimuthal direction. The two stations are usually situated in the polar cap, at the footprint of open geomagnetic field lines, but around local geomagnetic noon they approach, or even reach under particular geomagnetic conditions (Zhou et al., 2000), the polar cusp.

\section{Experimental results}

Variations in the Earth's magnetic field were measured in both observatories by means of three-axis fluxgate magnetometers. The field variations are measured along three directions oriented respectively with reference to the local magnetic meridian: the horizontal magnetic field intensity $\mathrm{H}$ component (south-north), the orthogonal-component $\mathrm{D}$ in the horizontal plane (west-east, then D is an intensive element, expressed consequently in $\mathrm{nT}$, and not the angular element declination) and the vertical intensity Z-component (consequently positive increase inward).

For this analysis we used 1 min values of the $\mathrm{H}$ horizontal geomagnetic field component at the two stations; TNB data are obtained averaging original 1-s measurements, with a resolution of $0.1 \mathrm{nT}$; SBA data, provided by the INTERMAGNET CD-ROMs, have a resolution of $0.1 \mathrm{nT}$ and an original sampling rate of $0.2 \mathrm{~Hz}$, according to the INTERMAGNET standard. We used the data recorded during the years 2001-2002; the data coverage in this period is of about 18 months, approximately fairly distributed in the three different Lloyd seasons (the time periods June-September 2001 and November-December 2002 are missing).

IMF data from ACE spacecraft, in their hourly averages, have been downloaded from OMNI database. For the comparison with geomagnetic observations, interplanetary data have been delayed by $1 \mathrm{~h}$ to take into account the average SW transit time from spacecraft position (at $\sim 235$ Re along the Sun-Earth direction) to Earth.

We analyzed the low frequency $(0.5-5 \mathrm{mHz}$, corresponding to periods $\sim 3-30 \mathrm{~min}$ ) geomagnetic field fluctuations measured at TNB and SBA geomagnetic observatories. This study focuses on the coherence and phase difference between 

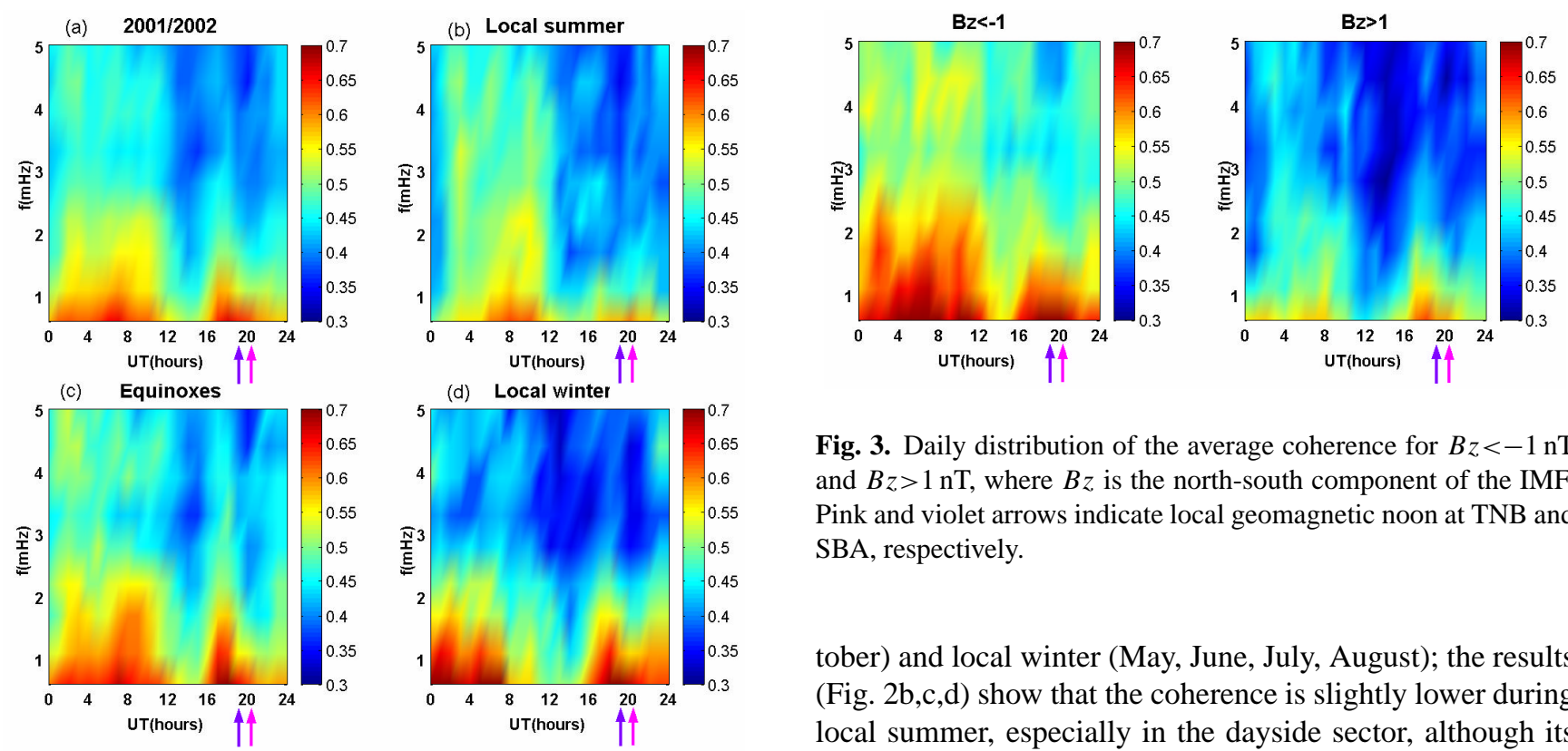

Fig. 3. Daily distribution of the average coherence for $B z<-1 \mathrm{nT}$ and $B z>1 \mathrm{nT}$, where $B z$ is the north-south component of the IMF. Pink and violet arrows indicate local geomagnetic noon at TNB and SBA, respectively.

Fig. 2. Daily distribution of the average coherence between fluctuations at TNB and SBA for: (a) the whole 2-years interval, (b) local summer, (c) equinoxes, (d) local winter. Pink and violet arrows in all the plots indicate local geomagnetic noon at TNB and SBA, respectively.

the fluctuations at the two stations. The analysis is conducted computing the coherence and phase difference for each 2-h interval (averaging four 30-min sub-intervals) with a stepsize of $1 \mathrm{~h}$, using the matlab processing tools, based on cross spectral density analysis. We defined the phase difference as the difference between the signal phase at SBA and that at $\mathrm{TNB}$, so its sign is positive or negative respectively for SBA or TNB observing the signal in advance.

In Fig. 2a the dynamic plot of the daily distribution of the average coherence between fluctuations at the two stations is reported. It is evident that the occurrence of coherent fluctuations is higher in the time period 00:00-12:00 UT, which corresponds in magnetic local time to the night time sector (16:00-04:00 MLT at TNB and 17:00-05:00 MLT at SBA); in this time sector the two stations are typically located well within the polar cap, far from the cusp. The average coherence also maximizes in the hours just before local geomagnetic noon (indicated in the plot by the arrows). We can note that the coherence generally decreases for increasing frequency, and this decrease is more steep in the daytime with respect to the night time sector. In the magnetic local morning, around 14:00 UT, the coherence is very low, even at the lowest frequencies.

We investigated the seasonal dependence of the average coherence, considering separately the three Lloyd seasons (Lloyd, 1861): local summer (January, February, November, December), equinoxes (March, April, September, Oct- 

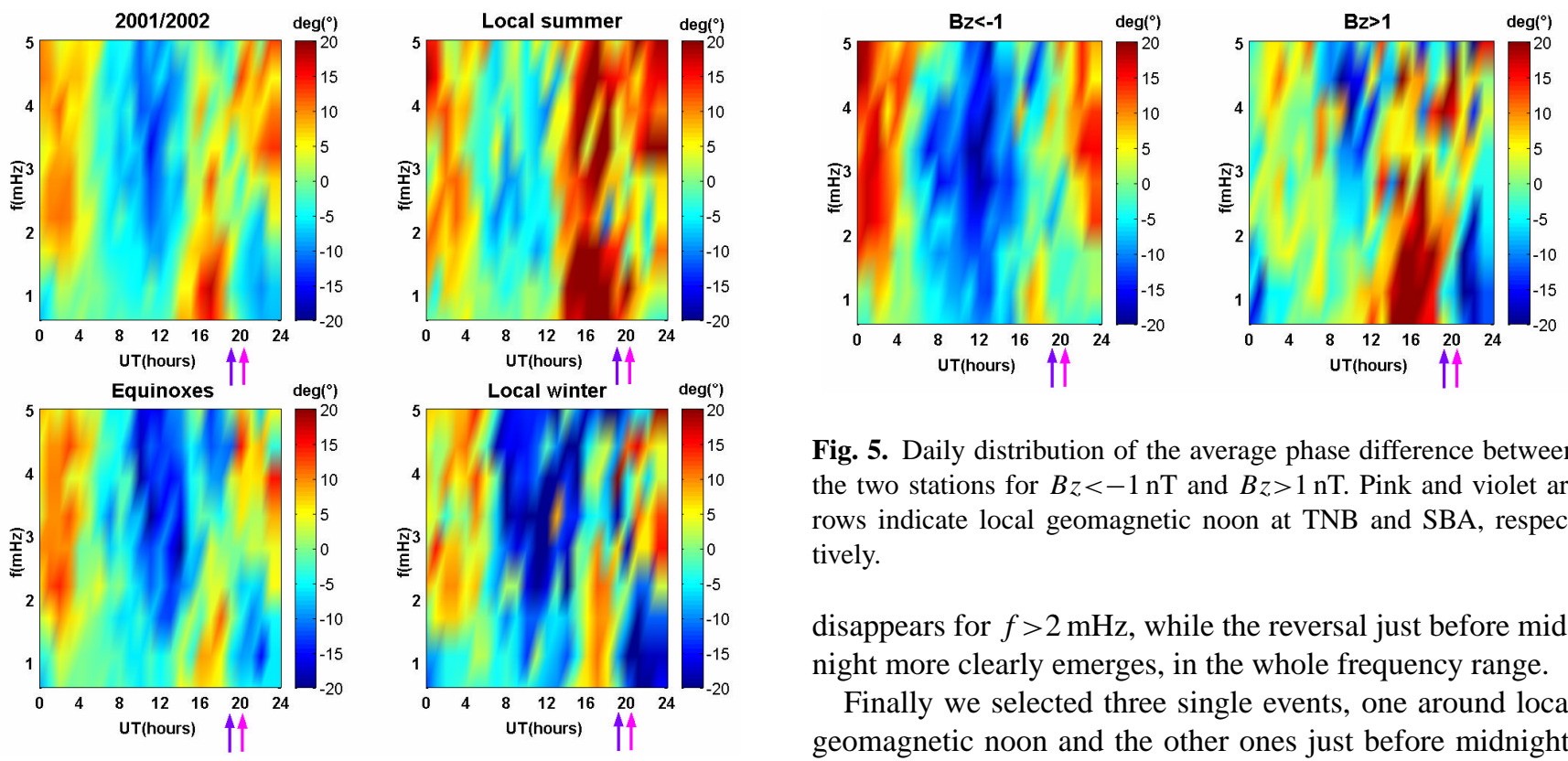

Fig. 5. Daily distribution of the average phase difference between the two stations for $B z<-1 \mathrm{nT}$ and $B z>1 \mathrm{nT}$. Pink and violet arrows indicate local geomagnetic noon at TNB and SBA, respectively.

disappears for $f>2 \mathrm{mHz}$, while the reversal just before midnight more clearly emerges, in the whole frequency range.

Finally we selected three single events, one around local geomagnetic noon and the other ones just before midnight, characterized by coherent fluctuations between the two stations and with a clear phase difference reversal. For each of the selected events we show in Figs. 6, 7 and 8 the $1-5 \mathrm{mHz}$ filtered data and the power spectra at TNB and SBA, together with the coherence and phase difference between the two stations. The power spectra were calculated with the maximum entropy method at order 15 of the prediction error filter over 60-min intervals with a step size of $30 \mathrm{~min}$; the coherence and phase difference were calculated with the same computational tools used for the statistical analysis, but decreasing the step size to $30 \mathrm{~min}$ in order to have an higher time resolution.

The first event occurs on 2 February 2001 in the time interval 15:00-23:00 UT (i.e. in the dayside sector), and is characterized by very quiet magnetospheric conditions $(K p<=1+)$, low SW speed $(\mathrm{Vsw}<400 \mathrm{~km} / \mathrm{s})$ and northward IMF. From Fig. 6 it is evident that, at both stations, there is a sustained wave activity between 16:00 and 22:00 UT, i.e. in the local noon sector, and that the fluctuations are quite similar at the two stations. Moreover, before 19:00 UT the fluctuation amplitude is greater at SBA, while after 20:00 UT it is greater at TNB, indicating an increasing amplitude approaching local geomagnetic noon. It can also be seen that around 17:00 UT (i.e. before local geomagnetic noon) SBA is leading with respect to TNB, while around 21:00 UT (after noon) TNB is leading with respect to SBA. All these features emerge also from the spectral, coherence and phase difference analysis (lower plots in Fig. 6): the power spectra at the two stations show several simultaneous enhancements most of which, at $f<\sim 2 \mathrm{mHz}$, are also highly coherent between the two stations: note in particular the wave packets around 17:00-18:30 UT and 20:00-22:00 UT. Moreover, as shown in the lowest plot, the phase difference very clearly reverses from positive to negative around 19:00 UT, indicating an azimuthal propagation away from noon. 

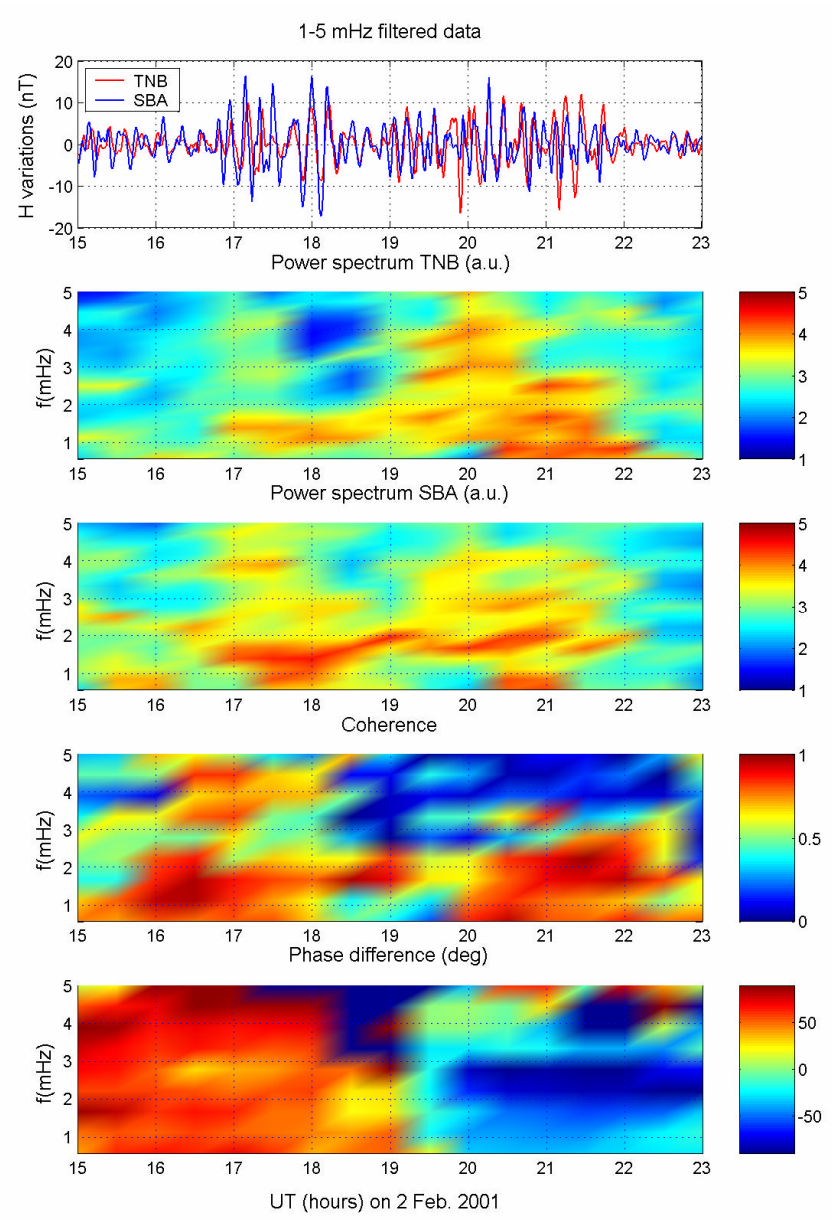

Fig. 6. Analysis of the event occurring between 15:00 and 23:00 UT on 2 February 2001. From top: variations of the geomagnetic field $\mathrm{H}$ component at the two stations, filtered in the $1-5 \mathrm{mHz}$ frequency range; power spectra at TNB and SBA; coherence and phase difference between the two stations. MLT noon at SBA and TNB is at 19:00 and 20:00 UT, respectively.

The second event occurs on 1 January 2001 between 02:00-08:00 UT (i.e. in the nightside sector, just before local magnetic midnight), in a time interval characterized by very quiet magnetospheric conditions $(\mathrm{Kp}<=1)$, low SW speed $(\mathrm{Vsw}<300 \mathrm{~km} / \mathrm{s})$ and southward IMF conditions $(B z \sim-2 \mathrm{nT})$. As shown in Fig. 7, the waves have a smaller amplitude and a more irregular appearance with respect to the previous event. The wave packets around 03:00 UT and 07:00 UT are characterized at the two stations by simultaneous power enhancements at the same frequencies ( $f \sim 1.5 \mathrm{mHz}$ and $f>\sim 3 \mathrm{mHz}$, respectively) and by high coherence; the phase difference corresponding to the two wave packets is opposite, indicating that SBA is leading with respect to TNB in the wave packet occurring before local geomagnetic midnight, while TNB is leading around midnight. For the wave packet around 03:00 UT this feature is evident, as a time shift, also from the filtered data; conversely, around
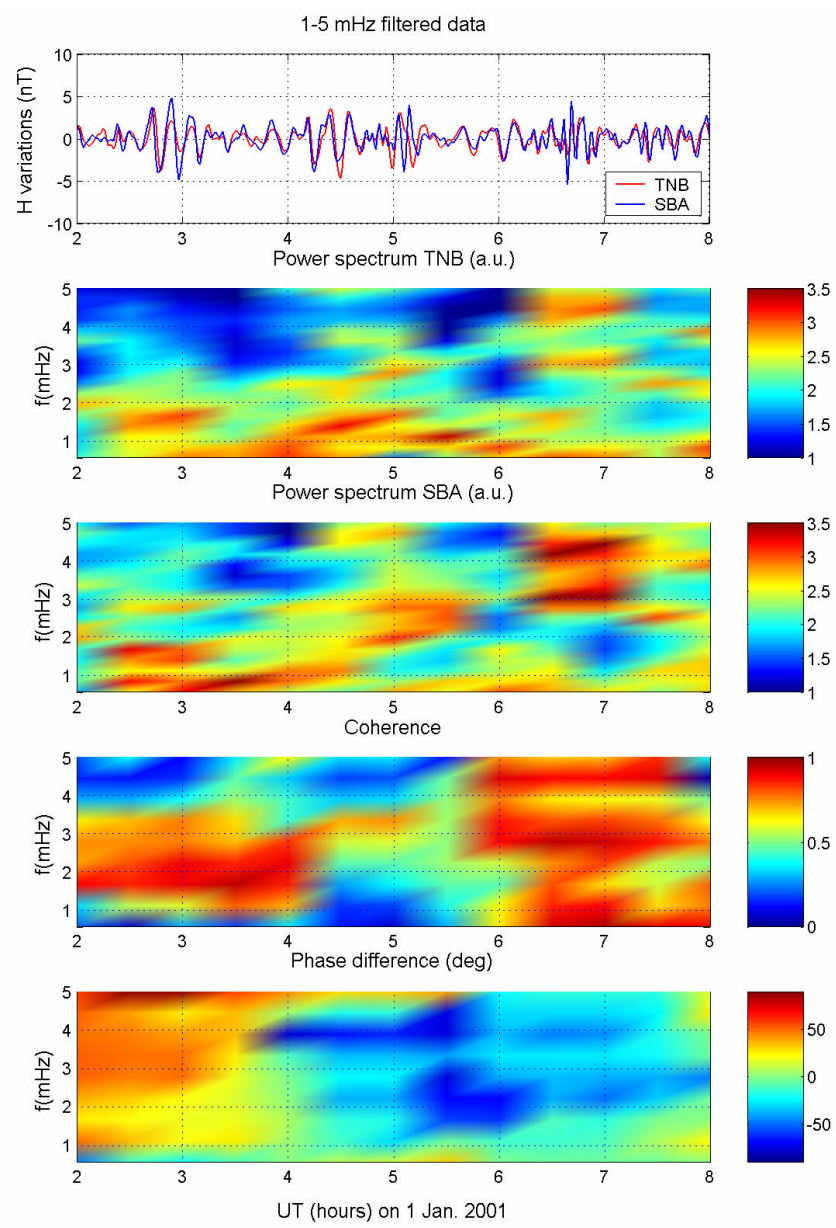

Fig. 7. The same of Fig. 6, for the event occurring between 02:00 and 08:00 UT on 1 January 2001. MLT midnight at SBA and TNB is at 07:00 and 08:00 UT, respectively.

07:00 UT it is harder to see, probably due to the higher wave frequency.

The third event occurs on 10 October 2001 between 00:00-12:00 UT (i.e. in the nightside sector), in a time interval characterized by fluctuating SW conditions, around standard values of the plasma parameters, and southward IMF $(B z \sim-4 \mathrm{nT})$ and corresponding to disturbed magnetospheric $(3<=K p<=4)$ and moderate storm (Dst $\sim 70$, Gonzalez et al., 1994) conditions.

As shown in Fig. 8, at both stations there is a sustained wave activity, in particular around 01:00-03:00 UT (corresponding to MLT late evening) and 07:00-11:00 UT (around and after MLT midnight). In both cases, the wave packets at the two stations show simultaneous power enhancements at the same frequencies and with high coherence; the phase difference is opposite, indicating that SBA is leading with respect to TNB in the late MLT evening, while TNB is leading after midnight. In both cases this feature can be seen, as a time shift, also in the filtered data. 

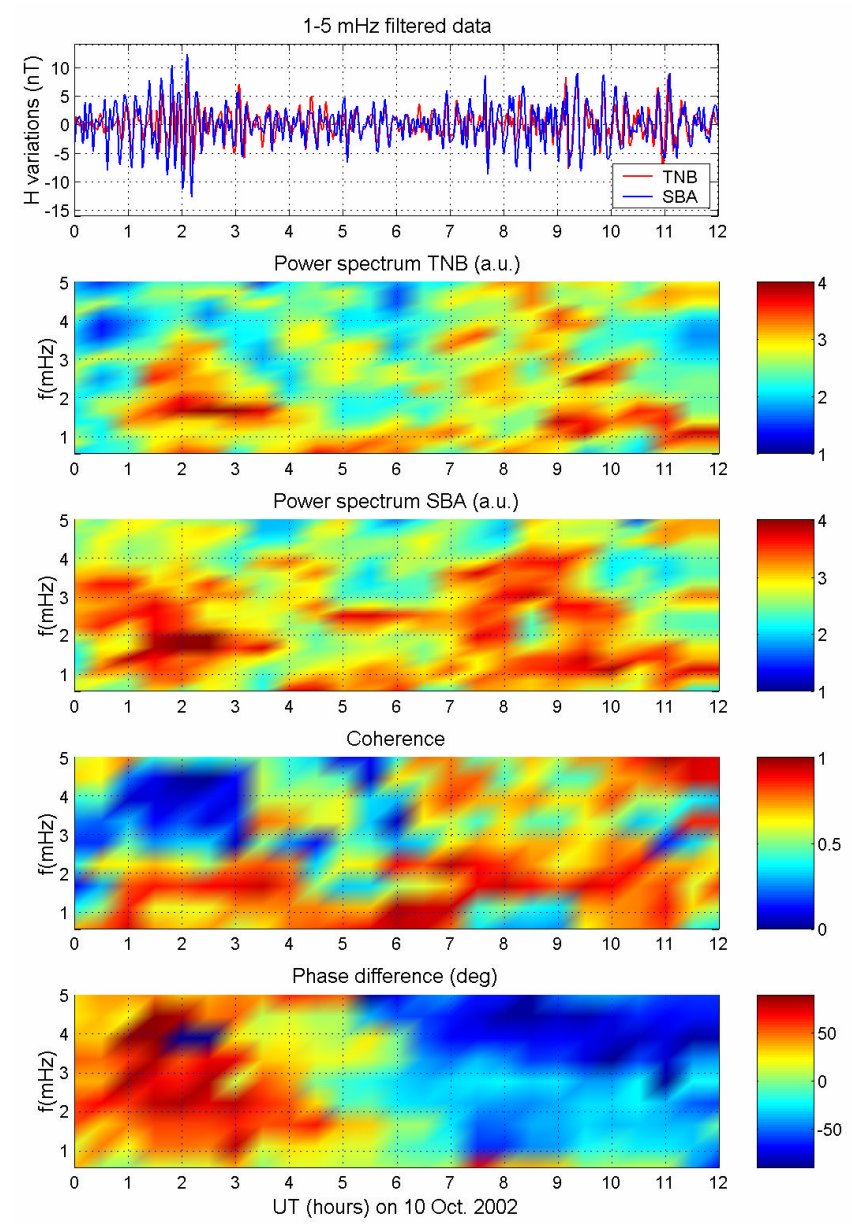

Fig. 8. The same of Fig. 6, for the event occurring between 00:00 and 12:00 UT on 10 October 2002. MLT midnight at SBA and TNB is at 07:00 and 08:00 UT, respectively.

\section{Summary and discussion}

In this paper we statistically analyze the coherence and phase difference between low frequency geomagnetic fluctuations at two Antarctic cap latitude stations, situated at the same geomagnetic latitude, with 1-h longitudinal displacement. The analysis is based on data recorded during two years, 20012002.

We found that coherent fluctuations are mostly detected in the hours around local geomagnetic midnight and, in a minor extend, noon. Also Yagova et al. (2002) reported the occurrence of coherent ULF waves $(1-6 \mathrm{mHz})$ within the polar cap in the night time sector; these waves have been interpreted in terms of the dynamics of the magnetotail (Ershkovich and Nusinov, 1972; Chen and Kivelson, 1991; Sarafopoulos, 1995). We also found that, both around midnight and noon, the coherence is higher during southward IMF conditions, i.e. fluctuations with larger spatial scale within the polar cap mostly occur during open magnetospheric condi- tions; conversely, during closed magnetospheric conditions the coherence is generally lower, indicating a shorter length scale of the observed phenomena.

For coherent fluctuations, we also conducted a phase difference analysis; the presence of a phase difference, due to a time delay between the phenomena observed at the two longitudinally displaced sites, indicates an azimuthal propagation; the sign of the phase difference indicates the propagation direction.

The average phase difference for coherent fluctuations reverses in the night time hours, just before local geomagnetic midnight, indicating a propagation direction away from midnight; this reversal is more clear for open magnetospheric conditions, suggesting a relation with substorm activity. Also Weatherwax et al. (1997) have observed at $80^{\circ} \mathrm{S}$ ULF geomagnetic oscillations (in the Pc5 range) superposed on riometer absorption events with an azimuthal motion directed westward premidnight and eastward postmidnight and point out that their observations can be explained in terms of substorm-related phenomena. Relevant research on these high latitude phenomena related to substorm activity has been conducted several years ago in the northern hemisphere (see for example Kangas et al., 1976; Olson, 1986 and the review by Heacock and Hunsucker, 1981). Our results show that for open magnetospheric conditions the geomagnetic phenomena propagating away from the midnight region are detectable on the ground as the dominant feature during the major part of the day, with the only exclusion of the local geomagnetic noon sector: indeed, the propagation direction is westward from the early afternoon until just before midnight; then around midnight it reverses and is steadily eastward not only in the postmidnight sector but also during the local morning, until around 09:00 MLT.

The phase difference for the lowest frequencies $(f<2-$ $3 \mathrm{mHz}$ ) fluctuations also reverses around local geomagnetic noon, indicating a propagation direction away from the subsolar point, as expected for a generation mechanism such as the KHI on the magnetopause. A previous statistical study of the polarization pattern of low frequency pulsations at TNB (Lepidi et al., 1999), has shown a polarization reversal around local geomagnetic noon, and also this result has been interpreted in terms of waves propagating away from the subsolar point. The phase difference reversal around noon for low frequency fluctuations is much more clear for closed magnetospheric conditions: indeed, in this case, the propagation direction is steadily directed away from the subsolar point during the whole dayside sector, approximately 09:0018:00 MLT. This finding is consistent with the results obtained by Miura (1995), who found from a two-dimensional model that the KHI is more likely to occur under northward IMF conditions.

We also investigated the seasonal dependence of the coherence and phase difference; the results show that the main difference emerges during local summer in the hours around local geomagnetic noon: the coherence is definitely lower 
and the phase reversal is less clear. This result can be interpreted taking into account the seasonal dependence of the dayside cusp average latitude (it occurs at higher latitude in the summer hemisphere), related to the change of the dipole tilt angle during the year (Newell and Meng, 1989; Zhou et al., 1999; Russell, 2000). In this sense, during summer the two stations in the daytime sector approach the cusp region, where local phenomena typically occur (Engebretson, 1995; Lanzerotti, 1999). Also Yagova et al. (2004) found a low spatial coherence for long period pulsations observed near the cusp projection, while the coherence is higher within the polar cap.

We also found interesting to conduct a study of individual pulsation events in order to find a correspondence with the general, statistical behaviour, in particular focusing on events for which it clearly emerges a reversal of the propagation direction. We have shown, as an example, three fluctuation events, one occurring around local geomagnetic noon and the other two around midnight.

The dayside event occurs during quiet magnetospheric and northward IMF conditions; conversely, both the nightside events occur during southward IMF conditions, one of them also during a moderate storm. These clear examples of waves propagating away from the local geomagnetic noon and midnight and are in agreement with the statistical result that the dayside and nightside phase reversals are associated with closed and open magnetospheric conditions, respectively. The nighttime events, in particular the one occurring during the geomagnetic storm, provide experimental evidence that coherent fluctuations around midnight can be related to storm or substorm phenomena.

Each of the three examples we analyze show quite unusual cases of coherent wave packets occurring within a few hours, extending from before to after the MLT noon (or midnight) phase reversal. More frequently, within one day, we observe just single coherent wave packets, whose phase difference agrees with the statistical results in the corresponding time period, but do not have the necessary temporal length to undergo a phase reversal. The scarcity of long duration, coherent fluctuation events is not surprising, in that our stations are located at the latitude $\left(80^{\circ} \mathrm{S}\right)$ where the amplitude and occurrence of Pc5-6 pulsations is minimum (Yagova et al., 2002); in this sense, also Baker et al. (2003) remark the absence of Pc5 pulsations within the polar cap. The event occurring before midnight is characterized by a definitely lower fluctuation amplitude with respect to the one around noon; in this sense we remind that around $80^{\circ} \mathrm{S}$ latitude the fluctuation power level maximizes around local geomagnetic noon, when the station approaches the polar cusp (Ballatore et al., 1998; Santarelli et al., 2003). Our results show that, although at $80^{\circ} \mathrm{S}$ there is not the power peak around midnight which is observed at cusp latitudes (Francia et al., 2005), the propagation direction of low frequency pulsations indicates the presence, around midnight, of substorm-related phenomena (Kangas et al., 1976; Olson, 1986); these nightime pulsations consist of short duration wave packets, while long duration trains can be sometimes detected in the daytime sector.

Acknowledgements. The research activity at TNB is supported by Italian PNRA (Programma Nazionale di Ricerche in Antartide). The authors thank the Institute of Geological \& Nuclear Sciences Limited (NEW ZEALAND) that operates the INTERMAGNET observatory SBA and in particular T. Hurst.

The authors thank the two referees for their helpful comments and suggestions.

Topical Editor I. A. Daglis thanks L. J. Lanzerotti and G. Balasis for their help in evaluating this paper.

\section{References}

Arnoldy, R. L., Cahill Jr., L. J., Engebretson, M. J., Lanzerotti, L. J., and Wolfe, A.: Review of hydromagnetic wave studies in the Antarctic, Rev. Geophys., 26, 181-207, 1988.

Atkinson, G. and Watanabe, T.: Surface waves in the magnetospheric boundary as a possible origin of long period geomagnetic micropulsations, Earth Planet. Sci. Lett. 1, 89-91, 1966.

Baker, G. J., Donovan, E. F., and Jackel, B. J.: A comprehensive survey of auroral latitude Pc5 pulsation characteristics , J. Geophys. Res., 108 (A10), 1384, doi:10.1029/2002JA009801, 2003.

Ballatore, P., Lanzerotti, L. J., and Maclennan, C. G.: Multistation measurements of Pc5 geomagnetic power amplitudes at high latitudes, J. Geophys. Res., 103(A12), 29 455-29466, doi:10.1029/1998JA900035, 1998.

Chen, S. H. and Kivelson, M. G.: On Ultralow frequency waves in the lobes of the Earths magnetotail, J. Geophys. Res., 96(A9), 15 711-15 723, 1991.

Engebretson, M. J., Hughes, W. J., and Alford, J. L.: Magnetometer array for cusp and cleft studies observations of the spatial extent of broadband ULF magnetic pulsations of cusp/cleft latitudes, J. Geophys. Res., 100, 19371-19386, 1995.

Ershkovich, A. I. and Nusinov, A. A.: Geomagnetic tail oscillations, Cosmic Electrodyn., 2, 471-480, 1972.

Francia, P., Lanzerotti, L. J., Villante, U., Lepidi, S., and Di Memmo, D.: A statistical analysis of low-frequency magnetic pulsations at cusp and cap latitudes in Antarctica, J. Geophys. Res, 110(A2), A02205, doi:10.1029/2004JA010680, 2005.

Gonzalez, W. D., Joselyn, J. A., Kamide, Y., Kroehl, H. W., Rostoker, G., Tsurutani, B. T., and Vasyliunas, V. M.: What is a geomagnetic storm?, J. Geophys. Res., 99, 5771-5792, 1994.

Gonzalez, W. D., Tsurutani, B. T., and Clua de Gonzalez, A. M.: Interplanetary origin of geomagnetic storms, Space Sci. Rev., 88, 529-562, 1999.

Heacock, R. R. and Hunsucker, R. D.: Type Pi 1-2 magnetic field pulsations, Space Sci. Rev., 28, 2, 191-221, 1981.

Kangas, J., Lukkari, L., and Heacock, R. R.: Observations of evening magnetic pulsations in the auroral zone during the substorm, J. Atmos. Terr. Phys., 38, 1177-1181, 1976.

Lanzerotti, L. J., Shono, A., Fukunishi, H., and Maclennan, C. G.: Long period hydromagnetic waves at very high geomagnetic latitudes, J. Geophys. Res., 104, 28 423-28 435, 1999.

Lepidi, S., Francia, P., Villante, U., Lanzerotti, L.J., and Meloni, A.: Polarization pattern of low-frequency geomagnetic field fluctuations $(0.8-3.6 \mathrm{mHz})$ at high and low latitude, J. Geophys. Res., 104(A1), 305-310, 1999. 
Lepidi, S., Cafarella, L., Francia, P., Meloni, A., Palangio, P., and Schott, J. J.: Low frequency geomagnetic field variations at Dome C (Antartica), Ann. Geophys., 21, 923-932, 2003, http://www.ann-geophys.net/21/923/2003/.

Lloyd, H.: On earth-currents, and their connexion with the diurnal changes of the horizontal magnetic needle. Trans. Roy. Irish Acad., 24, 115-141, 1861.

Lui, A. T. Y.: Current controversies in magnetospheric physics, Rev. Geophys., 39, 4, 535-563, 2001.

Meloni, A., Palangio, P., Cafarella, L., Romeo, G., Bozzo, E., and Caneva, G.: The geomagnetic observatory at Terra Nova Bay Base, Terra Antarctica, 1, 181-183, 1997.

Miura, A.: Dependence of the magnetopause Kelvin-Helmholtz instability on the orientation of the magnetosheath magnetic field, Geophys. Res. Lett., 22, 2993-2996, 1995.

Newell, P. T. and Meng,, C.-I.: Dipole tilt angle effects on the latitude of the cusp and cleft/low latitude boundary layer, J. Geophys. Res., 94, 6949-6953, 1989.

Olson, J. V.: ULF signatures of the polar cusp, J. Geophys. Res., 91, $10055-10062,1986$.

Phan, T. D., Escoubet, C. P., Rezeau, L., Treumann, R. A., Vaivads, A., Paschmann, G., Fuselier, S. A., Attié, D., Rogers, B., and Sonnerup, B. U. Ö.: Magnetopause Processes, Space Sci. Rev., 118, 367-424, 2005.

Russell, C. T.: The polar cusp, Adv. Space Res., 25, 1413-1424, 2000.

Samson, J. C.: Three-dimensional polarization characteristics of high latitude Pc5 geomagnetic micropulsations, J. Geophys. Res., 77, 6145-6160, 1972.

Santarelli, L., Lepidi, S., Palangio, P., and Cafarella, L.: Pc3-Pc4 pulsations at Terra Nova Bay (Antarctica): seasonal dependence of the power and its relation with solar wind parameters, Mem. S.A.It., 74, 766-769, 2003.
Sarafopoulos, D. V.: Long duration Pc5 compressional pulsations inside the Earth's magnetotail lobes, Ann. Geophys., 13, 926937, 1995, http://www.ann-geophys.net/13/926/1995/.

Villante, U., Lepidi, S., Francia, P., Meloni, A., and Palangio, P.: Long period geomagnetic field fluctuations at Terra Nova Bay (Antarctica), Geophys. Res. Lett., 24, 1443-1446, 1997.

Villante, U., Lepidi, S., Francia, P., Vellante, M., Meloni, A., and Palangio, P.: ULF fluctuations at Terra Nova Bay (Antarctica), Annali di Geofisica, 43(2), 217-227, 2000.

Weatherwax, A. T., Rosenberg, T. J., Maclennan, C. G., Doolittle, J. H. et al.: Substorm precipitation in the polar cap and associated Pc 5 modulation, Geophys. Res. Lett., 24(5), 579-582, 1997.

Yagova, N. V., Lanzerotti, L. J., Villante, U., Pilipenko, V. A., Lepidi, S., Francia, P., Papitashvili, V. O., and Rodger, A. S.: ULF Pc5-6 magnetic activity in the polar cap as observed along a geomagnetic meridian in Antarctica, J. Geophys. Res., 107, 1195, doi:10.1029/2001JA900143, 2002.

Yagova, N. V., Pilipenko, V. A., Lanzerotti, L. J., Engebretson, M. J., Rodger, A. S., Lepidi, S., and Papitashvili, V. O.: Two-dimensional structure of long-period pulsations at polar latitudes in Antarctica, J. Geophys. Res, 109, A03222, doi:10.1029/2003JA010166, 2004.

Ziesolleck, C. W. S. and McDiarmid, D. R.: Statistical survey of auroral latitude Pc5 spectral and polarization characteristics, J. Geophys. Res., 100, 19299-19312, 1995.

Zhou, X. W., Russell, C. T., Le, G., Fuselier, S. A., and Scudder, J. D.: Solar wind control of the polar cusp at high altitude, J. Geophys. Res., 105, 245-252, 2000. 